\title{
Enterprise Resource Planning Systems Implementation: Effects on Accounting Information Processing
}

\author{
Oladipupo Muhrtala Tijani ${ }^{1, *}$, Mathias Gboyega Ogundeji ${ }^{2}$ \\ ${ }^{1}$ Department of Accounting and Finance,Elizade University, Ondo-State, Nigeria \\ ${ }^{2}$ Mathias Gboyega Ogundeji \& Co. (Chartered Accountants and Tax Practitioners), 72/82, Kudirat Abiola Way, Suite A1, Humuani \\ Shopping Mall, Oregun, Ikeja, Lagos-Nigeria \\ *Corresponding Author: oladipupotijani@gmail.com
}

Copyright $@ 2014$ Horizon Research Publishing All rights reserved.

\begin{abstract}
The use of computerized accounting system has reached remarkable heights in recent years. However this pattern in developing economies does not seem to have attained similar strength. The era of technological sophistication has enabled the use of specialized transactions processing systems. Consequently this study chose to investigate the effects of enterprise resource planning systems on accounting information processing with particular reference to Nigerian. This paper builds upon the "technologies acceptance model" on factors influencing individual's choice of technology when faced with particular tasks. Using a survey approach and applying both descriptive and inferential statistics the study found significant use of enterprise resource planning systems on accounting information processing in Nigeria. This research sets a baseline for academia in bridging the theory and practise gap to continue to support scholars in learning computerized accounting information processing for practise relevance. In addition the use of computerized systems must remain within the ambience of generally accepted accounting principles and procedures to ensure the art continues to present true and fair view of underlying transactions for users of financial reports. This paper is unique in that there are no studies evidencing the use of enterprise resource planning systems in Nigeria. Hence, it is a fundamental point of reference for future research in this area.
\end{abstract}

Keywords Accounting Information Processing, Technological Sophistication, Transaction Processing Systems, Enterprise Resource Planning, Nigeria

JEL Classification: MO, M4, M15, M41

\section{Introduction}

Technology, one of the key drivers of globalization has revolutionized business in particular and the society in general in the past two decades (Spathis and Constantinides,
2004) [17]. It is no longer an afterthought in forming business strategies but the actual cause and driver. Events have revealed that business is no longer as usual in the corporate world. The ever increasing dynamism, complexity and snowballing competition brought about by the advent of globalization driven by information technology have radically transformed the face of business as Large and medium-sized organizations have experienced transformation into multinationals (Spathis and Constantinides, 2004) [17] with significant challenges to strategic information systems. Information systems now provide the channel for strategy adoption and business process reinvention forming a basis for continuous changes to ways in meeting customers growing complex and changing demands. These modifications have in due course influence business activities and the way firms process accounting information. Ultimately, corporations wishing to survive the occasion must discard the brick-and-mortar approach to financial transactions processing. The limitations experienced in the use of fragmented and incompatible legacy systems have been overcome by the development of the Enterprise Resource Planning (ERP) system (Robey, Ross \& Boudreau, 2002) [13]. The attraction of the motivation for enhanced business efficiency, streamlined operations, and increased cost savings has reinvigorate the adoption of ERP systems. It is increasingly becoming impossible to overestimate the growing adoption of enterprise resource planning (ERP) application as a business information integration platform for medium and large sized firms. The ERP, a concept coined by the Gartner group in early 1990 as the next generation of MRP II (Keller) (Riccio, 2000) [14] is an integrated enterprise-wide computing software system encompassing other sets of software modules underlined by a common database to process business functions such as basic finance, human resource, materials management, sales and distribution (Slater, 1998) [15]. Whether as open-source or proprietary software, ERP applications are built to support a single transaction flow through an entire applications collection and seamlessly updating financial and inventory records without 
the need for additional data entry through multiple applications. These packages cut across administrative as well as material resource planning in manufacturing. The rapid popularity of ERP systems is difficult to overstate as its use enabled nearly a $70 \%$ decline in accounting personnel through reduction in multiplicity of data redundancies across consolidated tasks (Larsen \& Myers, 1997) in Markus and Tanis, (2001) [8].

Approximately 19 percent of companies across all industries majorly manufacturing have installed and use the software (Carlsbad, 1999) [4], other 34 percent are at various stages of investigating, piloting and/or implementing ERP bundles. The application is designed to automate business process, produce real-time data, operate multiple language and currency capabilities for sharing common data across the organization to integrate global operations of multinationals (Robey, Ross \& Boudreau, 2002) [13]. Although ERP appear to assist organization achieve fundamental improvements in terms of business process reengineering, the primary benefits associated with the application may result from accommodating business growth, new business processes, improved organizational structures, human capital skill requirements and knowledge management (Davenport, 1998; Martin, 1998,) [5], [9]. Notwithstanding these benefits and more, the cost of ERP acquisition comes potentially high. These may include but not limited to initial license procurement, consultancy fees, staff training and annual license maintenance fee. Typical ERP project cost nearly over a hundred-million (\$100) dollars, especially when such acquisition involves installing multiple modules across several divisions (Shaw, 2000) [16]. Investments in ERP have also been reported to be risky due to its complexity as organizations adjust slowly to complete re-architecting of their portfolio of transactions-processing applications in order to achieve business processes, systems and information alongside related changes to supporting computing equipment and facilities (Markus \& Tanis, 2001) [8]. Eventually, about half of all ERP projects do not achieve anticipated benefits due to underestimating its change management requirements by managers, applications significant departure from original design speculations or missing project deadlines (Appleton, 1997) [1]. Ultimately the magnitudes of ERP failure are considerable with regard to resources consumption. Perhaps, with these linked complexities, corporations still continue to adopt ERP for both technical and business reasons.

There appears to be substantial literary evidence in academia and practice over extensive adoption of ERP systems in Western and Middle Eastern countries alike. Although the dawn of economic growth in developing economies is increasingly turning them into major targets for ERP vendors (O'Kane, 2002; Davidson, 2002; Huang et al., 2004) in (Otieno, 2010) [11], there seem to be little empirical support for implementation with particular reference to its perceived benefits and other implications for accounting information systems processing. In addition, the authors are unable to identify with any empirical study investigating the perceived benefits associated with the use of ERP systems. Subsequently, this paper aim to fill this gap through an empirical approach investigating the impact of ERP applications on accounting information systems processing of adopting companies in Nigerian. In determining the extent to which ERP systems has affected transactions processing in the companies examined, the emphasis is on significant changes in accounting information systems processes and procedure. The aim is to understand from users' perspective the likely benefits associated with ERP systems implementation in Nigeria, and provide recommendations for maximizing the effectiveness and efficiency of ERP software potentials to achieve sustained competitive advantages. The result of this study also serves as a platform for international comparison of ERP systems implementation.

\subsection{Aim and Objectives of the Study}

The aim of this study is to examine the effects of ERP systems implementation on accounting information processing, by investigating the perception of selected respondents. To achieve this aim, the study seeks to:

i. investigate respondents' perceptions on the reasons for ERP systems implementation;

ii. examine the perceptions of respondent groups on the impacts of ERP systems implementation on accounting information processing; and

iii. investigate whether significant benefits has been achieved with ERP systems after the adoption of ERP systems.

\subsection{Research Questions}

The study is intended to provide answers to the following research questions to achieve the objectives stated in earlier section:

i. what are the likely reasons for ERP systems implementation in Nigeria?

ii. to what extent do ERP systems implementation impact on financial transactions processing?

iii. to what extent has improvement been achieved in accounting information systems after the adoption of ERP systems?

\subsection{Research Hypotheses}

In order to provide answers to the aforementioned questions, the following null hypotheses have been identified:

H01: Adoption of ERP systems has no significant impacts on financial transactions processing?

H02: There are no significant improvements in accounting information systems subsequent to the adoption of ERP systems?

Research question "i" was not subjected to the formulation of hypothesis as it were subjected to descriptive analysis 
only.

\subsection{Scope of the Study}

This study is motivated by the spate of ERP systems implementation in developing economies. Therefore, the perceptions of selected company respondents were sought in providing answers to the questions raised in the study. For the purpose of the study, only organizations that had implemented ERP systems were taken into consideration after due consultation with major ERP providers in Nigeria. The focus of the research in terms of study group includes finance, accounts and other executives holding primary responsibilities for accounting information processing across oil and gas, manufacturing, construction and mining, hotel and hospitality, and IT services (including telecommunications) in responding organizations.

\section{Theoretical Framework}

After defining the objective of the study, it is pertinent that we provide explanation for this outcome of interest using a theory. The rational actor theories is however relevant here. The emphasis of the rational actor theory is that decision makers in organizations must be able to realize their goals. One of such prominent example of the rational actor theory is the technology acceptance model. The focus of this theory is that the basis for choice of technologies when organizations are faced with alternatives is the consideration of specific tasks (Markus and Tanis, 2001) [8]. Hence the basis for rational actor theories is the highlight of people's motivations and actions by which they are driven to achieve their goals. Therefore, it is almost impossible to overstate the importance of these theories. Wherever possible, organizations would take decisions regarding to the adoption of technology tools and equipment in cognizance with their ultimate objectives. These objectives might revolve around achieving efficiency and effectiveness in accounting information processing for improved decision making and actions. Since the ultimate goal of every business is to make profit, decisions capable of achieving worthwhile returns on investment in technologies would continue to drive information systems strategies. However, it is pertinent to note that these theories failed to consider other factors capable of influencing organizations choice of technology tools with which to drive their business processes.

\subsection{Empirical Studies}

There are studies in the literature on ERP systems implementation, utilization and challenges as well as key success factors amongst others experienced by adopting organizations, majority of which had their concentration technical rather than business with very little support for accounting implications. Some of those referred were conducted in Germany (Molnar, Szabo \& Benczur, 2013);
Greece (Kanellouu \& Spathis, 2011); France (Chitioui, 2009); U.K. (Kennerley \& Neely, 2001); to those in other parts of the world like India (Chaudhary, 2012; Ghuman \& Chaudhary, 2010); Taiwan (Chen, Chen \& Tsai, 2010); China (Savage, Callaghan, Dang \& Sun, 2010; Lin Hsu \& Ting, 2005; Jidong \& Liyan, 2010); Australia (Xu, Nord, Brown \& Nord, 2002); Poland (Zarzycka, 2010); Denmark, Slovakia and Slovenia (Sudzina \& Johansson, 2012); Finland (Hyyonen, 2010). Others were studies in Korea (Kwahk \& Lee, 2008); Hungary (Molnar et al., 2012); Turkey (Azaltun, Batibay, Calayoglu, Mert \& Tastan, 2013); and Brazil (Riccio, 2000); and Pakistan (Shash et al., 2011).

Different studies employed survey data. For instance, Spathis and Constantinides (2004) [17] presented a report evidencing the impact on accounting processes of companies adopting ERP systems in Greece. Using a combination of research interviews and postal questionnaire input through a list of factors identified encompassing users' reasons for ERP adoption, perceived benefits, as well as possible changes in accounting processes, the study featured respondents across companies in commerce, services and other industries. The outcome suggested that that the adoption of ERP systems are at their infancy in Greece as some changes in accounting processes have not been widely applied and that potential benefits from their adoption were non-significant. Benefits accruable to ERP implementation are often viewed from a long-term perspective (Poston \& Grabski, 2001) [12]. Nonetheless, the empirical evidence confirmed a number of changes in accounting processes introduced with ERP adoption in some of the responding firms. Most noteworthy amongst these include wide introduction of internal IS audit systems, adoption of non-financial performance indicators, and segmentation of performance appraisal (i.e. strategic business units, product and/or service units analysis, cost and profit centers). Although, the overall benefits associated with the use of ERP applications had been insignificant which might have been be due from size-effect relationship as the sample size was limited to only 26 respondents even at a 100 percent response rate, there were high ratings for perceived benefits received from the use of ERP systems. Essentially, there had been increased flexibility in producing reports, increased integration of accounts applications, and improved quality of financial reports leading to overall improvement in decision making process.

Through an empirical and qualitative research conducted on companies using ERP systems in Brazil, Riccio (2000) [14] presented a paper on the effects of ERP systems on the accounting function at the 5th international seminar on manufacturing accounting research. Exploring over 250 companies in Brazil with the FI/CO modules of ERP across retail, construction, construction supply, higien, drugs, and electronics industries the study concluded significant adoption of ERP systems in Brazil. The changes to accounting processes were considered by responding organizations as beneficial for the operations of their companies. Decentralization of the accounting function was 
also considered significant as separate modules and sub-modules were segregated by function across accounting units. The study also conveyed that for both nationals and multinationals alike, reasons for implementing ERP include the need to adopt corporate standard in their financial control, business process, information systems, and operation integration; need to have an integrated control administration coupled with integration of information to provide seamless access to accounting information and stronger control over operations of the accounting function; decrease in accounting paper details; and systems reliability. The study further revealed challenges during implementation phases identified by the surveyed firms amongst which are insufficient budget, customization, and knowledge of possibilities and alternatives of the system and few others which were mostly technical in nature.

In order to examine the auditing implications of enterprise resource planning systems, Azaltun et al. (2013) [2] compared the efficiency of ERP based systems audit with conventional computerized accounting systems audit in Turkey. Based on input from questionnaire copies sent to auditors of companies working with ERP systems, their conclusions suggested significant reduction in audit costs for those firms as public accountancy practices offering professional auditing services offered such at reduced charges to their customers using ERP. Even though the study found substantial reduction in operational audit turnaround time about ERP based systems, it nevertheless emphasize the need for auditors to be properly trained about ERP based audit in order to facilitate thorough understanding of systems, processes, risk response activities and internal control of ERP clients' environment. However, the study failed to consider factors such as classification of audit tools and technologies adopted, skills and knowledge of auditors, complexity of clients' system (in terms of transaction volume and cycle), social engineering and other dynamics capable of influencing technology-based auditing.

Kanellou and Spathis (2011) [7] explored the impact that ERP systems has on accounting information and practice by examining whether differences exist between professional accountants and IT professionals as regards their assessment of ERP accounting benefits. Using data obtained from 175 accountants and 96 IT professionals from 193 companies in Greece, the study confirmed a number of accounting benefits derivable from ERP systems particularly in accounting processes. These include IT accounting benefits, operational efficiency, company-wide and managerial accounting benefits. Nevertheless, this study is very limited in scope as it only reviewed restricted benefits delineated in the survey instrument.

There are also indications that that the prominence of ERP systems is not restricted to large-sized firms. Mirbagheri and Khajavi, (2013) [10] in an empirical investigation of the importance of ERP systems implementation analyzed a five dimensions benefit in Malaysian SME's. While identifying a combination of tangible and non-tangible component factors amongst which were operational, managerial, strategic, IT infrastructure, and organizational benefits, the study produced a very high response rate of 89 percent on survey amongst eighty-four companies sampled. Findings suggested that SME's are unable to secure comparable gains attributed to ERP systems implementation as compared to multinationals and other large-sized firms. There are also indications that the likelihood of implementation failure is higher amongst small and medium firms as compared to their larger counterparts. However, the most significant benefits ranked included efficient resource management, improved decision making, support for business growth, business process flexibility amongst others.

ERP systems do evolve with peculiar challenges similar to other implications of IT. In a study carried out by Soltanzadeh and Khoshsirat (2012) [18], the challenges of ERP implementation as a technology transfer project was examined. An explanatory factor analysis (EFA) producing direct insight into the inter-relationships between the variables studied revealed critical success factors integrating ERP implementation and technology transfer. The authors concluded that factors such as culture, organizational structure, project management policies, training and support activities, and cooperation between end-user and vendor support were the most significant challenges for ERP systems implementation.

Although the presence of ERP system vendors, support service agents, end-users amongst large corporations including multinationals and other complex entities suggests obvious deployment of the application in Nigeria, the authors are unaware of the existence of empirical literary support for its use, in particular, the accounting module of the integrated application.

\section{Research Methodology}

This study adopted a survey approach. The design is considered suitable due to its ability to comprehensively view the major questions raised directly. The population is made of finance and accounts executives holding primary responsibilities for transactions processing and ultimately reporting for financial reporting in responding organizations using ERP systems in Nigeria. The reflected input from respondents covered oil and gas, manufacturing, construction and mining, hotel and hospitality, and IT services industries. Primary data was obtained through carefully drafted questionnaire designed divided into two (2) sections. The first was designed to capture information on respondents' demographic details while the second section was designed to assess respondents' perception of the use of ERP systems on their accounting processes. The instrument was constructed on a five-point Likert type scale (1 through 5) with responses ranging from "strong agreement" to "strong disagreement" requiring the subjects to indicate their opinion along each of the indicated statements. Analysis of data was conducted using both descriptive and inferential statistics. While descriptive method was used to analyze input on the 
reasons for adoption of ERP systems by responding companies while hypotheses formulated to provide answers to questions two and three were subsequently tested using analysis of variance (ANOVA). Analysis was carried out with the aid of Statistical Package for Social Sciences, (SPSS for Windows Version 18.0, 2009) software.

\subsection{Sample and Data Collection}

In order to achieve the objectives identified earlier, a sample size of forty (40) was targeted for each group across all industries. The choice of this sample is guided by literature on the minimum threshold (practical sample size) of not less than thirty (30) subjects in any group category for statistical tests (Balian, 1994; Denscombe, 2003) [3], [6]. The instrument was pre-tested prior to distribution for consistency, clarity and relevance. The initial testing was aimed at ten (10) other groups not included in the final survey but are current adopters of ERP systems. Reliability testing produced a Cronbach's alpha coefficient of 0.831 and verified appropriate. In this estimation, the final sampling error was calculated in $9.72 \%$ which was also considered acceptable for an investigation without previously known parameters. Subsequently, minor changes requested by the test group relating to the content of the instrument in terms of wording, sentence construction, and sequence were effected in the final draft. With objective assessment from the pre-test procedure generating an average completion time of 7 minutes, the final copies were produced afterwards. In cognizance of the limitations attributed to hard-copy survey instruments, the authors consider an online approach more suitable for this study. Hence, questionnaire input were obtained via online digital submission using "Google Documents" created with same questionnaire style. Subsequently, the link was shared and publicized via email and posted on professional digital discussion fora. Thereafter the raw data were logged on Microsoft spread-sheet and downloaded for analysis. The result of distribution and usable success rate is presented in the next session.

\section{Data Analysis and Results}

The input obtained from questionnaire was used in classifying the subjects into the various industries namely oil and gas, manufacturing, construction and mining, hotel and hospitality, and IT services industries. Out of the two hundred (200) copies of instruments administered, only one hundred and forty two (142) were returned duly completed and used for analysis. This represents an overall response rate of 71 percent for all groups. Subsequently, the responses were used in providing answers to the research questions raised earlier in the study. Information on responses from each group of respondents is offered in Table 1.

The result presented in the table revealed that according to the questionnaire the proportion of respondent input was the highest in the oil and gas industry recording a response rate of 36 representing 90 percent input. This figure was followed by manufacturing sector with 78 percent. Thereafter IT services 73 percent; hotel and hospitality 60 percent; and construction recorded the lowest response rate of 55 percent. We may therefore suggest that the industry with the highest users of ERP systems is the oil and gas. The authors are of the opinion that this may be borne out of the possibility that majority of the operators in the oil and gas surveyed are large and multinational corporations operating as subsidiaries of parent companies mostly in developed economies.

Table 1. Questionnaire distribution and responses

\begin{tabular}{|c|c|c|c|}
\hline Industry & $\begin{array}{c}\text { Number of } \\
\text { Survey }\end{array}$ & $\begin{array}{c}\text { Number of } \\
\text { responses }\end{array}$ & $\begin{array}{c}\% \text { of } \\
\text { responses }\end{array}$ \\
\hline Oil and Gas & 40 & 36 & $90 \%$ \\
\hline Manufacturing & 40 & 31 & $78 \%$ \\
\hline Construction and Mining & 40 & 22 & $55 \%$ \\
\hline Hotel and Hospitality & 40 & 24 & $60 \%$ \\
\hline IT Services & 40 & 29 & $73 \%$ \\
\hline Total & 200 & 142 & $71 \%$ \\
\hline
\end{tabular}

Source: Analysis of survey data (2013).

\subsection{Major Reasons for Implementing ERP Systems}

Findings of this study revealed that the main factor responsible for ERP implementation in Nigeria is information systems integration with 57 percent. It follows industry capacity requirements, which amounted to 47 percent of the sample; business process reengineering accounted for 43 percent; cost reduction was 26 percent, and the little clarity on taxation requirements showed 14 percent. The authors are of the opinion that the reasons information systems integration and industry capacity requirements constitute major influence on ERP implementation is due from majority of responding companies being subsidiaries of multinationals. Hence, their use of ERP systems essentially group-wide information systems policies.

\subsection{Test of Research Hypotheses}

In order to provide answers to the hypothesis derived, two main factors were identified and aligned along other subsequent variables. Taking into account the correlations between these factors and variables, the factors were interpreted and named accordingly. The first component comprised the variables concerning improved efficiency of transactions processing cycles and seamless tracking of revenue and expenditures (which is understood as impact on financial transactions processing). This component factor was established as viability for the impact of ERP systems on survey firms' accounting information systems. The second group of variables comprises the improved quality of reports for decision making and improved flexibility and integration of accounting modules. This group was 
associated with the improvements suggested in the accounting information systems subsequent to the deployment of ERP systems.

In the last stage of the study, a logistic regression was performed to establish whether ERP systems implementation had significant influence on the variables identified. For that purpose, the selected dependent variable (factors) was "the use of ERP systems" and the independent variables were the variables delineated in two groups identified in the factorial analysis. This subsequently constituted the basis for rejecting or accepting the hypotheses recognized.

\subsubsection{Hypothesis One}

H01: Adoption of ERP systems has no significant impacts on financial transactions processing?

For the purpose of this analysis, the respondents cut across the five (5) industries. H1 concerned the impacts of ERP systems implementation on financial transactions processing in Nigeria. Two (2) items from the instrument (statements 1 and 8) are associated with this hypothesis. The result of the hypothesis proposed is shown in Table 2.

The variables in the equation in Table 2 provide output on the predictor variables. The Wald test revealed the value of the statistic for each predictor. As evidenced, propensity in the impact of ERP systems on financial transactions processing is significant with $(\operatorname{Exp}(B)=0.712)$ and $(\operatorname{Exp}(B)$ $=1.002$ ) for improved efficiency of transactions processing cycles and seamless tracking of revenue and expenditures respectively. With this, we are able to reject the null hypothesis $\left(\mathrm{H}_{01}\right)$ and accept the alternative. This suggests that the adoption of ERP systems has significant impact on financial transactions processing.

\subsubsection{Hypothesis Two}

H02: There are no significant improvements in accounting information systems subsequent to the adoption of ERP systems

The second hypothesis proposed is concerned with respondents view about ERP systems implementation on accounting information systems (AIS) as a whole. This hypothesis was tested using statements 2 and 7 in the survey instrument. Result presented in Table 3 revealed for both statements $(\operatorname{Exp}(B)=0.734)$ and $(\operatorname{Exp}(B)=1.292)$. These two statements were used to model whether there are significant improvements brought about by ERP on accounting information systems by adopting companies. With the use of the deployment of ERP systems by surveyed entities as control variable in the result presented, we are able to reject the null hypothesis and accept the alternative. Conclusively, our result suggested that there are significant improvements to accounting information systems of ERP systems adopting organizations in Nigeria.

From these decision rules, it can be concluded that ERP implementation, in its entirety has significant implications for accounting information processing in Nigeria.

Table 2. Results of Logistics Regression

Variables in the Equation

\begin{tabular}{|c|c|c|c|c|c|c|c|c|c|}
\hline & \multirow{2}{*}{$\mathrm{B}$} & & \multirow{2}{*}{ S.E. } & \multirow{2}{*}{ Wald } & \multirow{2}{*}{ df } & \multirow{2}{*}{ Sig. } & \multirow{2}{*}{$\operatorname{Exp}(B)$} & \multicolumn{2}{|c|}{$95 \%$ C.I.for $\operatorname{EXP}(B)$} \\
\hline & & & & & & & & Lower & Upper \\
\hline \multirow{3}{*}{ Step $1^{\mathrm{a}}$} & $\begin{array}{c}\text { Improved Efficiency of } \\
\text { Transactions Processing } \\
\text { Cycles }\end{array}$ & -.340 & .300 & 1.288 & 1 & .006 & .712 & .395 & 1.281 \\
\hline & $\begin{array}{c}\text { Seamless Tracking of } \\
\text { Revenue and Expenditures }\end{array}$ & .002 & .308 & .000 & 1 & .016 & 1.002 & .548 & 1.832 \\
\hline & Constant & 2.847 & 1.012 & 7.912 & 1 & .005 & 17.237 & & \\
\hline
\end{tabular}

Variable(s) entered on step 1: Improved Efficiency of Transactions Processing, Seamless Tracking of Revenue and Expenditures.

Table 3. Results of Logistics Regression

Variables in the Equation

\begin{tabular}{|c|c|c|c|c|c|c|c|c|c|}
\hline & & \multirow[b]{2}{*}{ B } & \multirow[b]{2}{*}{ S.E. } & \multirow[b]{2}{*}{ Wald } & \multirow[b]{2}{*}{ df } & \multirow[b]{2}{*}{ Sig. } & \multirow[b]{2}{*}{$\operatorname{Exp}(B)$} & \multicolumn{2}{|c|}{ 95\% C.I.for $\operatorname{EXP}(\mathrm{B})$} \\
\hline & & & & & & & & Lower & Upper \\
\hline \multirow[t]{3}{*}{ Step $1^{a}$} & $\begin{array}{l}\text { Improved Quality of Reports for } \\
\text { Decision Making }\end{array}$ & -.310 & .405 & .584 & 1 & .000 & .734 & .332 & 1.623 \\
\hline & $\begin{array}{l}\text { Improved Flexibility and } \\
\text { Integration of Accounting } \\
\text { Modules }\end{array}$ & .256 & .373 & .471 & 1 & .002 & 1.292 & .622 & 2.682 \\
\hline & Constant & 1.829 & 1.016 & 3.24 & 1 & .072 & 6.23 & & \\
\hline
\end{tabular}

a. Variable(s) entered on step 1: Improved Quality of Reports for Decision Making, Improved Flexibility and Integration of Accounting Modules. 


\section{Conclusion}

This study examined the effects of enterprise resource planning systems implementation on accounting information processing in Nigeria. Results suggested that the major reasons for companies adopting ERP systems are the integration of accounting information systems and industry-wide requirements. It was also concluded from the results of the Kruskal-Wallis model test that the use of ERP systems has significant contributions for accounting information processing as it supports efficiency in transactions processing and accounting modules integration. The findings of this study agrees substantially with Azaltun et al. (2013) [2] in Turkey where they concluded that the reasons companies adopt ERP systems is to standardize business processes. It also complemented the findings of Spathis and Constantinides (2004) [17] in Greece the authors reported that the adoption of ERP systems is useful in accounting processes integration.

\section{REFERENCES}

[1] Appleton, E.How to Survive ERP. Datamation, Vol. 3, No. 3, pp. 50-53, 1997

[2] Azaltun, M., Batibay, I., Calayoglu, I., Mert, H., \& Tastan, H. The Impact of Enterprise Resource Planning (ERP) System on the Cost and Price of Auditing - Auditors Perspective. Journal of Modern Accounting and Auditing, Vol. 9, No. 4, pp. 497-504, 2013.

[3] Balian, E. The Graduate research Guidebook: A Practical Approach to doctoral/masters research. Maryland: University Press of America. 1994.

[4] Carlsbad, C. Computer Economics. Proceedings of Annual Information Systems and eBusiness Study . pp. 18-22, U.S.A.: Computer Economics. 1999

[5] Davenport, T. (1999). Living with ERP. CIO Magazine, Vol. 12, No. 5, ((1998), pp. 30,32.

[6] Denscombe, M. The good research guide for small-scale social research projects. (2nd ed.). Maidenhead-Philadelphia:
Open University Press. 2003

[7] Kanellou, A., \& Spathis, C. (2011). Proceedings of 8th International Conference on Enterprise Systems, Accounting and Logistics, pp. 360-367, Thassos Island, Greece. 2011

[8] Markus, M. \& Tanis, C. The Enterprise System ExperienceFrom Adoption to Success. U.S.A.: Oxbridge. 1997.

[9] Martin, J. Cultures in Organizations: Three Perspectives. U.S.A.: Oxford University Press. 1992.

[10] Mirbagheri, F. \& Khajavi, G. Impact of ERP Implementation at Malaysian Firms SME's: Analysis of Five Dimensions Benefit, International Journal of Enterprise Computing and Business Systems, Vol. 2, No. 1, pp. 1-15, 2013.

[11] Otieno, J. Enterprise Resource Planning Systems Implementation and Upgrade. Middlesex University, U.K.: School of Engineering and Information Science. 2010.

[12] Poston, R. \& Grabski, S. Financial Impacts of Enterprise Resource Planning Systems Implementation. International Journal of Accounting Information Systems, Vol. 2, pp. 271-294. 2001.

[13] Robey, D., Ross, J., \& Boudreau, M. (2002). Learning to Implement Enterprise Systems: An Exploratory Study of the Dialectics of Change. Journal of Management Information Systems, Vol. 19, No. 1, (Summer, 2002, pp. 17-46.

[14] Riccio, E. Analysis of the Effects of ERP systems in Accounting Organization. Proceedings of 5th International Seminar on Manufacturing Accounting Research, pp. 1-13, Brazil, 2000.

[15] Slater, D. The Hidden Costs of Enterprise Software, CIO Magazine, Vol. 11, No. 7, pp. 48-55. 1998.

[16] Shaw, M. All Syetsm go. Pulp and Paper, Vol. 79, No. 4, pp. 39-45. 2000.

[17] Spathis, C., \& Constantinides, S. Enterprise Resource Planning Systems' Impact on Accounting Processes, Business Process Management Journal, Vol. 10, No. 2, pp. 234-247. 2004.

[18] Soltanzadeh, J. \& Khoshsirat, M. Proceedings of International Conference on Economics, Business Innovation, IPEDR, Vol. 38, pp. 16-22. Singapore, 2012. 